\title{
Propriedades físicas do solo em função de manejos em lavouras de cafeeiro conilon ${ }^{1}$
}

\author{
Teóphilo André Maretto Effgen²; Renato Ribeiro Passos ${ }^{3 *}$; Felipe Vaz Andrade ${ }^{3}$; Julião Soares de Souza Lima ${ }^{4}$; \\ Edvaldo Fialho dos Reis ${ }^{4}$; Elias Nascentes Borges ${ }^{5}$
}

\begin{abstract}
RESUMO
Os solos de uso agrícola estão sujeitos a modificações em suas propriedades, de acordo com o tipo de uso e sistemas de manejo adotados. Este trabalho teve como objetivo avaliar, em diferentes locais de amostragem, as propriedades físicas de solos cultivados com lavouras cafeeiras, sob distintos manejos, no sul do Estado do Espírito Santo. Foram realizadas amostragens nas camadas de 0,00-0,20 m e 0,20-0,40 m, na parte superior da projeção da "saia” do cafeeiro, em relação ao sentido de declive do terreno. Foram utilizadas, para o estudo, lavouras representativas da região sul do Estado, apresentando a mesma classe de solo (Latossolo Vermelho-Amarelo distrófico, relevo forte ondulado), tendo os seguintes manejos: M1 - irrigação por gotejamento, calagem a cada dois anos, adubação, roçadas e uso da palha de café; M2 - adubação, roçadas e capinas; M3 - capinas e roçadas. Em cada manejo, foram avaliados os seguintes locais de amostragem: TS - terço superior, TM - terço médio; TI - terço inferior, ao longo do declive. As propriedades físicas avaliadas foram: densidade do solo, porosidade total, macroporosidade, microporosidade e resistência do solo à penetração. Para as condições experimentais, a resistência do solo à penetração, a macroporosidade e a microporosidade mostraram-se importantes indicadores físicos da qualidade do solo, influenciados pelo manejo, local de amostragem e camada avaliada.
\end{abstract}

Palavras-chave: estrutura do solo, uso do solo, Coffea canephora Pierre ex Froehner.

\section{ABSTRACT}

\section{Physical soil properties as a function of management in crops of conilon coffee}

Agricultural soils are subject to change in their properties, according to the type of use and management systems adopted. The objective of this study was to evaluate, in different sampling sites, the physical properties of soils cultivated with conilon coffee under different managements in the South of Espirito Santo State, Brazil. Samples were collected from the layers 0,00-0,20 $\mathrm{m}$ and 0,20-0,40 $\mathrm{m}$ in the upper part of the coffee plant canopy, in relation to the direction of the slope. Coffee crops, representative of the South of the Espirito Santo State, with the same soil class (dystrophic Red Yellow Latosol (Oxisol) hilly relief), were used for the study, including the following managements: M1 - drip irrigation, liming every two years, fertilization, cleared and use of the straw of conilon; M2 - manuring, cleared and weedings; M3 - weedings and mowing. For each management, the following sampling sites were evaluated: UT upper third, MT - medium third; LT - lower third, along the slope. The physical soil properties evaluated were: bulk density, total porosity, macroporosity, microporosity and soil resistance penetration. For the experimental conditions, the soil resistance penetration, the macroporosity and microporosity important physical indicators of the quality of the soil were shown, influenced by the management, sampling site and evaluation depth.

Key words: soil structure, soil use, Coffea canephora Pierre ex Froehner.

Recebido para publicação em 06/12/2011 e aprovado em 19/06/2012

${ }^{1}$ Parte da Dissertação de Mestrado do primeiro autor, apresentada ao Programa de Pós-Graduação em Produção Vegetal, CCA-UFES.

2Engenheiro-Agrônomo, Mestre. Instituto de Defesa Agropecuária e Florestal do Espírito Santo (IDAF), Avenida Nossa Senhora da Penha, 396, Bairro Castelo, 29360-000, Espírito Santo, Brasil. teoeffgen@yahoo.com.br

${ }^{3}$ Engenheiro-Agrônomo, Doutor. Departamento de Produção Vegetal (CCA-UFES), Universidade Federal do Esrírito Santo, Alto Universitário, s/n, 29500-000, Alegre, Espírito Santo, Brasil. renatoribeiropassos@hotmail.com; felipevazandrade@gmail.com (*Autor para correspondência.)

${ }^{4}$ Engenheiro Agrícola, Doutor. Departamento de Engenharia Rural, (CCA-UFES), Universidade Federal do Espírito Santo, Alto Universitário, s/n, 29500-000, Alegre, Espírito Santo,Brasil. limajss@yahoo.com.br; edreis@cca.ufes.br

${ }_{5}^{5}$ Engenheiro-Agrônomo, Doutor. Instituto de Ciências Agrárias (ICIAG/UFU), Universidade Federal de Uberlândia, Avenida Amazonas, s/n, Bairro Umuarama, 38400-902, Uberlândia, Minas Gerais, Brasil. elias@ufu.br 


\section{INTRODUÇÃO}

O café é produto importante no mundo econômico, tanto para os países em desenvolvimento, onde é produzido, quanto para os industrializados, que são os principais consumidores. A produção do café conilon e as atividades dela resultantes geram, nos variados setores, renda e empregos de forma significativa (Matiello, 1998). Entretanto, para a obtenção de produções sustentáveis, é necessário o conhecimento dos atributos do solo, indicativos de sua qualidade, bem como do ambiente em que se encontram.

O Estado do Espírito Santo destaca-se por ser o maior produtor de café conilon do país e, por suas características de relevo e clima, possui diversas formas de manejo para uma mesma cultura. No sul do Estado do Espírito Santo a maioria das lavouras encontra-se em propriedades de agricultura familiar e situadas em regiões declivosas (Matiello, 1998).

Para o desenvolvimento de uma cafeicultura sustentável, alguns atributos do solo são importantes, pois podem atuar como indicadores de qualidade do solo. Esses atributos devem ser sensíveis às variações do manejo, bem correlacionados com as funções desempenhadas pelo solo, capazes de elucidar os processos do ecossistema, serem compreensíveis e úteis para o agricultor e, preferencialmente, de fácil mensuração. Devem, ainda, ser sensíveis às alterações na qualidade do solo, induzidas por modificações recentes no manejo (Conceição et al., 2005). Os indicadores físicos da qualidade do solo devem estar relacionados com o arranjo estrutural das partículas sólidas e à porosidade e refletir limitações ao desenvolvimento radicular, à emergência das plântulas, ao movimento de água no perfil e, consequentemente, à potencialidade produtiva. Associados a esses fatores devem revelar alterações estruturais provocadas pela adoção de determinado sistema de manejo, assim como problemas relacionados com a compactação, ao encrostamento superficial e à susceptibilidade à erosão (Lima et al., 2007). Dentre esses indicadores, encontram-se a densidade, a porosidade total, a macroporosidade, a microporosidade, a resistência à penetração e a umidade do solo.

O efeito de sistemas de uso e manejo sobre as propriedades físicas do solo e culturas tem sido temas de várias pesquisas (Beutler et al., 2004; Silva et al., 2005; Spera et al., 2009; Nunes et al., 2010). A caracterização dessas propriedades nos diferentes sistemas de manejo adotados pelos agricultores possibilita selecionar aqueles que conduzem a uma maior produtividade das culturas, com menor interferência negativa no meio ambiente.

Este trabalho objetivou avaliar, em diferentes locais de amostragem, as propriedades físicas de solos em lavouras cafeeiras da variedade conilon, cultivadas sob distintos manejos no sul do Estado do Espírito Santo.

\section{MATERIAL E MÉTODOS}

Para a condução dos trabalhos, foram selecionadas três lavouras de café representativas da região, com sete a oito anos de implantação, submetidas a diferentes manejos, em condição de relevo forte ondulado (Embrapa, 1999), localizadas no município de Jerônimo Monteiro, nas coordenadas $20^{\circ} 47^{\prime} 25^{\prime \prime} \mathrm{S}$ e $41^{\circ} 23^{\prime} 48^{\prime \prime} \mathrm{W}$, com altitude entre $120 \mathrm{~m}$, situadas na Bacia Hidrográfica do Rio Itapemirim, no sul do Estado do Espírito Santo. A espécie de café cultivada é o café conilon (Coffea canephora Pierre ex Froehner), proveniente de mudas clonais.

O clima é classificado, segundo Köppen, como sendo do tipo Aw, com estação seca no inverno e verão quente e chuvoso. A temperatura média anual é de $26^{\circ} \mathrm{C}$. Os solos em que as três lavouras de café estão implantadas foram classificados como Latossolo Vermelho-Amarelo distrófico e de textura argilosa, com teores médios de argila de $410 \mathrm{~g} \mathrm{~kg}^{-1}$ e $499 \mathrm{~g} \mathrm{~kg}^{-1}$, respectivamente, nas camadas de 0,00-0,20 m e 0,20-0,40 m.

As lavouras cafeeiras distinguem-se quanto ao manejo aplicado (M1, M2 e M3 conforme descrito a seguir). Em cada manejo foram locados, ao longo do declive do terreno, três locais de amostragem (TS - terço superior; TM terço médio; e TI - terço inferior), sendo consideradas regiões exportadoras de materiais.

A área onde está implantada a lavoura sob o manejo denominado M1 foi utilizada anteriormente para a atividade de pastagem, sendo o café conilon implantado há 14 anos (ano de 1998), com espaçamento de 1,50 x $2,50 \mathrm{~m}$. A capina manual foi realizada nos quatro primeiros anos, com duas operações por ano. Posteriormente, passou-se a adotar as roçadas (duas por ano). Decorridos três anos de implantação da lavoura, foi implantado o sistema de irrigação por gotejamento. A calagem é feita a cada dois anos e, a adubação, parcelada em duas vezes por ano, utilizando-se formulados com NPK, sendo o 25-05-20, o mais utilizado. O retorno da palha de café para a lavoura é feito após o seu beneficiamento na propriedade, sendo distribuída alternadamente, ou seja, em um ano é distribuída de cima para baixo e no outro ano, de baixo para cima, por não ser a palha do café beneficiado na propriedade suficiente para ser distribuída na área total cultivada. A declividade da lavoura, no TS, é de 22\%, no TM, é de $26 \%$, e no TI, é de $35 \%$.

A área onde está implantada a lavoura sob o manejo denominado M2 foi utilizada anteriormente para o cultivo de citros, sendo o café conilon implantado há 13 anos (ano de 1999), com espaçamento de 1,60 x 2,30 m. A capina manual é feita de duas a três vezes por ano e, a roçada, uma vez por ano. Durante o plantio, foi feita a calagem na cova, sendo que, posteriormente, não se 
utilizou mais a calagem. A adubação é parcelada em duas vezes por ano e feita utilizando-se adubos à base de ureia e $\mathrm{KCl}$. A poda do café conilon começou a ser realizada quatro anos após a implantação da lavoura. A declividade da lavoura, no TS, é de $24 \%$, no TM, é de $28 \%$ e, no TI, é de $30 \%$.

A área onde está implantada a lavoura sob o manejo denominado M3 foi utilizada anteriormente para pastagem, sendo o café conilon implantado há 14 anos (ano de 1998), com espaçamento de 1,50 x 2,60 m. A capina manual é feita de três a quatro vezes por ano e as roçadas são em número de duas por ano. No plantio, foi feita a calagem a lanço na superfície do terreno, sendo que posteriormente não se utilizou mais a calagem. Não é feita adubação. Junto com a lavoura, é realizado o cultivo de culturas anuais como o milho, que é plantado em outubro ou novembro, e o feijão, que é plantado em março ou abril. Não é feita a poda na lavoura cafeeira. A declividade da lavoura, no TS, é de $28 \%$, no TM, é de $30 \%$ e, no TI, é de $41 \%$.

Para avaliação das propriedades físicas do solo, foram retiradas amostras deformadas (utilizando-se um trado do tipo holandês), indeformadas (utilizando-se amostrador tipo Uhland), e medida a resistência do solo à penetração nas camadas de 0,00-0,20 m e 0,20-0,40 m do solo, na parte superior da projeção da “saia” do cafeeiro, em relação ao sentido de declive do terreno. Em cada manejo, foram avaliados três locais de amostragem (TS, TM e TI), ao longo do declive. Foram feitas cinco repetições em cada local de amostragem e camada.

As propriedades físicas do solo avaliadas foram: densidade do solo (Ds), pelo método do anel volumétrico; porosidade total (P), calculada pela expressão $\mathrm{P}=1$ - Ds/ Dp; macro e microporosidade, com a utilização do extrator de Richards a tensão de 0,006 MPa; umidade do solo, pelo método termogravimétrico (Embrapa, 1997) e resistência do solo à penetração, com a utilização de penetrômetro de impacto (Stolf, 1991).

Em áreas de relevo forte ondulado, a divisão das áreas em segmentos (terços superior, médio e inferior), para avaliação das condições de solo, faz-se necessária, dada à heterogeneidade, em geral, observada para as propriedades físicas estudadas.

As propriedades físicas do solo foram analisadas, utilizando-se o delineamento inteiramente casualizado, distribuído em esquema de parcelas subdivididas, tendo nas parcelas os tipos de manejos adotados (M1, M2 e M3) e, nas subparcelas, os locais de amostragem (TS, TM e TI), com cinco repetições, nas camadas de 0,00-0,20 e 0,20$0,40 \mathrm{~m}$. Os dados experimentais foram submetidos à análise de variância, e teste “F”, e, posteriormente, foi aplicado o teste de Tukey, a 5\%, para comparação entre as médias, por meio do software SAEG.

\section{RESULTADOS E DISCUSSÃO}

\section{Densidade do solo, porosidade total, macroporosidade e microporosidade}

Os resultados apresentados na Tabela 1, para a densidade do solo, mostram que os manejos M1 e M3 proporcionaram diferenças significativas quanto ao local de amostragem nas duas camadas estudadas. Na camada de 0,00-0,20 m, são encontrados elevados valores de densidade do solo, conforme Camargo \& Alleoni (1997), que consideram valores compreendidos na faixa de 1,0 a 1,2 $\mathrm{kg} \mathrm{dm}^{-3}$ como ideais para solos de textura argilosa, evidenciando o quanto essa propriedade é influenciada pelos manejos adotados nas lavouras cafeeiras, em todos os locais de amostragem, o que é confirmado por Gontijo (2003). Esses elevados valores de densidade do solo podem estar relacionados com o processo constante de umedecimento e secagem e com o impacto de gotas de chuvas sobre a superfície do solo, favorecendo a desagregação e remoção de partículas e contribuindo para a translocação de partículas mais finas para os horizontes inferiores, causando entupimento dos poros (Nunes et al., 2010). Podem estar relacionados , também, com o efeito de capinas e roçadas que atuam na estrutura do solo.

Para a camada de 0,20-0,40 m, verifica-se, para o manejo M1, que os valores de densidade do solo encontrados para o local de amostragem TI diferiram dos demais locais (Tabela 1). O maior valor de densidade do solo encontrado em TI, no manejo M1, possivelmente está relacionado com as práticas culturais empregadas na lavoura cafeeira, tais como adubação e calagem que favorecem a dispersão da argila e consequente movimentação ao longo do declive, bem como, por ser a região que recebe todo o material da lavoura proveniente das enxurradas. No manejo M3, distintamente do M1, verifica-se, em ambas as camadas, que o local de amostragem TM não diferiu de TS e este último não diferiu de TI (Tabela 1). Os menores valores de densidade do solo encontrados no TI podem estar associados à não utilização de adubação e calagem nesta lavoura, desfavorecendo a dispersão da argila e sua movimentação do TS em direção ao TI. Para o manejo M2, não houve diferença significativa nas duas camadas estudadas, entre os locais de amostragem, ou seja, os manejos empregados na lavoura não interferiram nessa propriedade em relação aos locais de amostragem.

Quando se comparam os valores de densidade do solo, entre os manejos (M1, M2 e M3), para cada local de amostragem, observa-se que para o TS não houve diferença entre os manejos, em ambas as camadas (Tabela 1). Para o TM, os efeitos do manejo M1 diferiram dos efeitos dos manejos M2 e M3, na camada superficial (0,00 - 0,20 $\mathrm{m})$. Na camada de 0,20-0,40 m, os efeitos dos manejos M1 e M2 diferiram dos do manejo M3. Os menores valores 
para densidade do solo observados no TM do solo sob manejo M1, da camada superficial, podem estar associados ao manejo cultural empregado, como o uso da palha do café e roçadas, que mantém uma cobertura vegetal sobre o solo. Para o local TI, verifica-se que, para a camada de 0,00-0,20 m, os efeitos do manejo M1 não diferiram dos efeitos do M2, que, por sua vez não diferiram dos efeitos do M3. Esses valores diferenciados da densidade do solo podem estar associados ao manejo e ao declive do terreno e ao histórico das áreas onde estão implantadas as três lavouras cafeeiras, que, anteriormente, eram destinadas à pastagem ou ao cultivo de citros.

De acordo com Richart et al. (2005), não existe consenso entre os autores sobre o nível crítico da densidade do solo, ou seja, o valor acima do qual o solo é considerado compactado. Contudo, segundo Camargo \& Alleoni (1997), para solos argilosos, estes valores estão compreendidos na faixa de 1,0 a $1,2 \mathrm{~kg} \mathrm{dm}^{-3}$. Percebe-se, neste trabalho, que os valores de densidade do solo, em ambas as camadas, independentemente do manejo e do local de amostragem, estão acima dos valores médios considerados ideais para densidade do solo, propostos por Camargo \& Alleoni (1997).

Os elevados valores de densidade do solo indicam uma possível compactação ou adensamento do solo. Matiello et al. (2005), em experimento com vasos, avalian- do mudas de cafeeiro arábica, notaram que suas raízes foram capazes de ultrapassar camadas de solo com Ds até $1,2 \mathrm{~kg} \mathrm{dm}^{-3}$, enquanto, em Ds variando de 1,20 a 1,35 kg $\mathrm{dm}^{-3}$, houve restrição ao crescimento radicular.

Elevados valores de densidade do solo podem atuar como fator limitante ao desenvolvimento e produtividade do cafeeiro, haja vista que a maior parte do sistema radicular ativo do cafeeiro encontra-se até a profundidade de 0,30 m (Guimarães \& Lopes, 1986), sendo o desenvolvimento das raízes prejudicado em condições de compactação do solo (Matiello et al., 2005).

A compactação ou adensamento nas camadas superficiais de solos sob cultivo, caracterizada por elevados valores de densidade, é comumente associada à redução da porosidade total e da macroporosidade. De acordo com Dexter (2004), a degradação da estrutura do solo resulta na sua compactação, o que ocasiona redução do volume de macroporos e mudanças na continuidade e distribuição de poros. Pela Tabela 1, para a porosidade total, percebe-se que não existe diferença significativa entre os locais de amostragem, dentro de cada trato cultural, nas camadas avaliadas, para essa característica. Entretanto, comparando-se os efeitos dos manejos, dentro de cada local de amostragem, verifica-se que ocorrem diferenças significativas entre os do TM e os do TI. Semelhantemente ao ocorrido para a densidade do solo, não houve diferen-

Tabela 1. Valores médios da densidade do solo, porosidade total, macroporosidade e microporosidade, nas camadas de 0,00-0,20 e 0,20-0,40 m do solo, obtidos em lavouras de cafeeiro conilon cultivadas sob distintos manejos e em diferentes locais de amostragem $^{1}$

\begin{tabular}{|c|c|c|c|c|c|c|}
\hline \multirow{3}{*}{ Manejos $^{2}$} & \multirow{2}{*}{\multicolumn{3}{|c|}{$\begin{array}{c}\text { Camada } 0,00-0,20 \text { m } \\
\text { Locais de amostragem }^{3}\end{array}$}} & \multirow{2}{*}{\multicolumn{3}{|c|}{$\begin{array}{c}\text { Camada } 0,20-0,40 \mathrm{~m} \\
\text { Locais de amostragem }\end{array}$}} \\
\hline & & & & & & \\
\hline & TS & TM & TI & TS & TM & TI \\
\hline & \multicolumn{6}{|c|}{ Densidade do solo $\left(\mathrm{kg} \mathrm{dm}^{-3}\right)$} \\
\hline M1 & $1,40 \mathrm{ABa}$ & $1,36 \mathrm{Bb}$ & $1,46 \mathrm{Aa}$ & $1,31 \mathrm{Ba}$ & $1,31 \mathrm{Bb}$ & 1,46 Аа \\
\hline M2 & $1,41 \mathrm{Aa}$ & $1,44 \mathrm{Aa}$ & 1,43 Aab & 1,33 Аа & $1,30 \mathrm{Ab}$ & $1,32 \mathrm{Ab}$ \\
\hline \multirow[t]{2}{*}{ M3 } & $1,44 \mathrm{ABa}$ & 1,46 Аа & $1,37 \mathrm{Bb}$ & $1,37 \mathrm{ABa}$ & 1,38 Аа & $1,30 \mathrm{Bb}$ \\
\hline & \multicolumn{6}{|c|}{ Porosidade Total $\left(\mathrm{m}^{3} \mathrm{~m}^{-3}\right)$} \\
\hline M1 & $0,473 \mathrm{Aa}$ & $0,488 \mathrm{Aa}$ & $0,451 \mathrm{Ab}$ & $0,498 \mathrm{Aa}$ & $0,500 \mathrm{Aa}$ & $0,444 \mathrm{Ab}$ \\
\hline M2 & $0,467 \mathrm{Aa}$ & $0,457 \mathrm{Ab}$ & 0,462 Aab & 0,490 Аа & 0,503 Аа & 0,496 Aa \\
\hline \multirow[t]{2}{*}{ M3 } & 0,460 Аа & $0,448 \mathrm{Ab}$ & 0,483 Аа & 0,477 Аа & $0,471 \mathrm{Ab}$ & 0,504 Aa \\
\hline & \multicolumn{6}{|c|}{ Macroporosidade $\left(\mathrm{m}^{3} \mathrm{~m}^{-3}\right)$} \\
\hline M1 & $0,137 \mathrm{Aa}$ & $0,172 \mathrm{Aa}$ & $0,142 \mathrm{Aa}$ & $0,159 \mathrm{Aa}$ & $0,171 \mathrm{Aa}$ & $0,121 \mathrm{Aa}$ \\
\hline M2 & 0,118 Аа & 0,097 Ab & 0,093 Ab & 0,113 Ва & 0,125 ABab & 0,170 Аа \\
\hline \multirow[t]{2}{*}{ M3 } & 0,130 Аа & $0,086 \mathrm{Ab}$ & 0,138 Аа & 0,134 Аа & 0,099 Ab & 0,125 Aa \\
\hline & \multicolumn{6}{|c|}{ Microporosidade $\left(\mathrm{m}^{3} \mathrm{~m}^{-3}\right)$} \\
\hline$\overline{\text { M1 }}$ & $0,336 \mathrm{Aa}$ & $0,316 \mathrm{Ab}$ & $0,309 \mathrm{Ab}$ & 0,339 Aa & $0,329 \mathrm{Ab}$ & $0,323 \mathrm{Ab}$ \\
\hline M2 & $0,349 \mathrm{Aa}$ & $0,360 \mathrm{Aa}$ & 0,369 Аа & 0,377 Аа & $0,378 \mathrm{Aa}$ & $0,326 \mathrm{Ab}$ \\
\hline M3 & 0,330 Аа & 0,362 Аа & $0,345 \mathrm{Aa}$ & 0,343 Аа & 0,372 Аа & 0,379 Аа \\
\hline
\end{tabular}

${ }^{1}$ Médias seguidas da mesma letra, maiúscula na linha e minúscula na coluna, não diferem entre si, pelo teste de Tukey a 5\%.

${ }^{2}$ M1 - irrigação por gotejamento, calagem a cada dois anos, adubação química, roçadas e uso da palha de café; M2 - adubação química, roçadas e capinas; M3 - capinas e roçadas.

${ }^{3}$ TS - terço superior; TM - terço médio; TI - terço inferior. 
ça significativa dos valores de porosidade total entre os manejos, para o TS, em ambas as camadas (Tabela 1). No TM, na camada de 0,00-0,20 m, os maiores valores de porosidade total foram encontrados em M1 (Tabela 1), mostrando que o manejo, com o uso de roçadas e de palha de café, influencia positivamente sobre essa propriedade. Nunes et al. (2010) verificaram que a recepa do cafeeiro promoveu o aumento da porosidade do solo, haja vista que os resíduos orgânicos que permanecem no solo sofrem ação dos micro-organismos e com a morte de raízes os espaços ocupados por elas podem ter-se tornado poros biológicos. Entretanto, para o TI, observa-se comportamento distinto, sendo os menores valores de porosidade total verificados sob M1, nas camadas de 0,00-0,20 e 0,200,40 m (Tabela 1), o que está associado aos maiores valores de densidade do solo encontrados nestes tratamentos, dada a relação inversa existente entre a porosidade total e a densidade do solo. Apesar de os valores de densidade do solo serem considerados elevados (Camargo \& Alleoni, 1997), observa-se que os valores de porosidade total, independentemente do local de amostragem, manejo adotado e camada estudada, encontram-se, segundo Brady (1989), dentro do intervalo considerado ideal para solos argilosos. Contudo, segundo Guimarães \& Lopes (1986), na camada de 0,00-0,20 m os valores de porosidade total encontram-se abaixo do valor considerado ideal para as plantas de café, que corresponde a 50\%.

Para a macroporosidade (Tabela 1), nota-se que, na camada de 0,00-0,20 m, não houve diferença significativa, para os locais de amostragem, dentro dos manejos (M1, M2 e M3). Comportamento semelhante é observado para M1 e M3 na camada de 0,20-0,40 m. Quando se avaliam os manejos dentro dos locais de amostragem, verifica-se, para TS, na camada superficial do solo (0,00-0,20 m), como na camada subsuperficial $(0,20$ - 0,40 m), para TS e TI, que não houve diferença significativa entre os efeitos dos manejos adotados. Para os demais locais, nota-se que há diferença significativa entre os efeitos dos manejos. Os valores elevados de Ds e reduzidos de MaP (Tabela 1), possivelmente, estariam favorecendo a erosão do solo e o arraste das partículas, como silte e argila, ao longo do declive do terreno.

Em termos de distribuição dos poros do solo (Tabela 1), a macroporosidade variou de 0,08 a $0,17 \mathrm{~m}^{3} \mathrm{~m}^{-3}$, na camada de 0,00-0,20 m e 0,09 a $0,17 \mathrm{~m}^{3} \mathrm{~m}^{-3}$, na camada de 0,20-0,40 m. Valores semelhantes também foram encontrados por Pedrotti et al. (2003), em Latossolo VermelhoAmarelo. Segundo Vomocil \& Flocker (1966), o volume mínimo de macroporos necessário ao crescimento e desenvolvimento satisfatório do sistema radicular corresponde a $0,1 \mathrm{~m}^{3} \mathrm{~m}^{-3}$, o que, de acordo com os resultados apresentados, caracterizaria um ambiente desfavorável à cultura do café, no TM e TI do trato cultural M2, na cama- da de 0,00-0,20 m, e no TM do trato M3, nas duas camadas estudadas, podendo ser considerados locais restritivos, por causa da importância dos macroporos na difusão da solução do solo. De acordo com Watanabe et al. (2002), valores de porosidade com ar abaixo de 10-15\% são geralmente adotados como restritivos para o crescimento e produtividade da maioria das culturas, apesar da dependência da espécie de planta e da atividade biológica do solo e do regime de umidade do solo.

Os elevados valores de densidade do solo e reduzidos valores de macroporosidade (Tabela 1) podem estar associados ao uso de capinas, que deixam o solo desnudo e favorecem a desagregação da estrutura do solo, por impactos das gotas de chuva, deixando partículas dispersas que são arrastadas para o interior dos poros, causando aumento na densidade e redução na porosidade total do solo, o que é corroborado por Alcântara (1997). O rearranjamento das partículas do solo, acarretando aumento da sua densidade, redução da porosidade total e, principalmente, da macroporosidade do solo, em função do trato cultural empregado na lavoura cafeeira, poderá ocasionar dificuldades das plantas de café em aprofundarem-se e emitirem radicelas. De acordo com Hatano et al. (1988), existe uma estreita relação entre a macroporosidade do solo e o crescimento radicular, sendo o crescimento de raízes maior quando há maior número e continuidade de macroporos.

Para a microporosidade (Tabela 1), percebe-se que não existe diferença significativa entre os locais de amostragem, dentro de cada manejo (M1, M2 e M3), nas duas camadas avaliadas. Quando se comparam os manejos adotados, dentro de cada local de amostragem, nota-se que não ocorreu diferença significativa, para o local TS, entre os manejos adotados, em ambas as camadas avaliadas. Verifica-se, ainda, para TM, em ambas as camadas, e TI, na camada de 0,0-0,20 m, que os valores de microporosidade observados em M2 e M3 não diferiram, sendo que M1 apresentou os menores valores de microporosidade. O fato de a maioria dos tratamentos estudados não apresentarem diferenças para microporosidade pode indicar que a textura argilosa está tendo maior influência, sobre esta propriedade física, do que o manejo e o local de amostragem.

Pela Tabela 1, verifica-se, ainda, que há um predomínio de microporos no solo em relação aos macroporos. Os elevados valores de Ds na camada superficial do solo (0,00-0,20 m), associados à redução da macroporosidade, podem contribuir para dificultar o movimento de ar e água, conforme salientado por Ribon et al. (2002), principalmente para as raízes do cafeeiro, pois a maioria das raízes ativas do cafeeiro encontra-se na profundidade de 0,30 m (Guimarães \& Lopes, 1986). Deve-se ressaltar que o fluxo de gases e o movimento de água no solo estão intima- 
mente relacionados com o volume de macroporos, ou seja, a garantia da oxigenação radicular,bem como a capacidade de infiltração e redistribuição de água no perfil dependem desse atributo.

De acordo com Reichert et al. (2003), para avaliação da estrutura do solo, os atributos densidade, porosidade total, macro e microporosidade são indicadores utilizados, sendo o monitoramento da qualidade do solo por meio dessas características importante para a manutenção e avaliação da sustentabilidade dos sistemas agrícolas.

\section{Resistência do solo à penetração e umidade do solo}

Dentre os manejos estudados, na camada de 0,00$0,20 \mathrm{~m}$, verifica-se que os efeitos de M3 diferiram significativamente dos de M2 que, por sua vez, diferiram dos de M1, apresentando M3 os maiores valores para resistência do solo à penetração (Tabela 2). Os menores valores de resistência do solo à penetração, encontrados em M1, podem indicar a importância da palha de café, associada aos maiores valores de umidade encontrados no solo sob M1, embora não tenham diferido dos de M2 (Tabela 3). Araújo et al. (2007), em estudo feito sobre qualidade do solo (QS) sob diferentes usos e sob cerrado nativo, verificaram que, dentre os atributos físicos testados, a resistência mecânica à penetração vertical refletiu com nitidez as diferenças de QS entre as áreas avaliadas, sendo uma propriedade de fácil e rápida quantificação em campo. Contudo, de acordo com estes autores, para ser válida, requer teores similares de umidade do solo nas áreas a serem comparadas.

Quando se avaliam os manejos adotados dentro dos locais de amostragem, na camada de 0,20-0,40 m, verifica-se que os efeitos de M3 diferiram estatisticamente dos de M1 e M2 (Tabela 2), apresentando os de M3 valores superiores, em todas os locais de amostragem (TS, TM e TI), indicando que os dados desta propriedade estão sendo influenciados pelo manejo e camada de amostragem. Os elevados valores de resistência do solo à penetração, observados sob M3, em ambas as camadas estudadas, podem estar associados aos menores teores de umidade do solo sob este trato cultural (Tabela 3), pois a resistência do solo à penetração aumenta à medida que a umidade do solo diminui (Araújo et al., 2004; Silveira et al., 2010).

Os valores apresentados na Tabela 2, para a resistência do solo à penetração, na camada de 0,00-0,20 m do solo, para M3, e na camada de 0,20-0,40 m, independentemente dos manejos adotados e dos locais de amostragem, estão acima de 5,1 MPa. Valores dessa magnitude podem

Tabela 1. Valores médios da densidade do solo, porosidade total, macroporosidade e microporosidade, nas camadas de 0,00-0,20 e 0,20-0,40 m do solo, obtidos em lavouras de cafeeiro conilon cultivadas sob distintos manejos e em diferentes locais de amostragem $^{1}$

\begin{tabular}{|c|c|c|c|c|c|c|}
\hline \multirow{3}{*}{ Manejos $^{2}$} & \multicolumn{3}{|c|}{ Camada 0,00-0,20 m } & \multicolumn{3}{|c|}{ Camada 0,20-0,40 m } \\
\hline & \multicolumn{3}{|c|}{ Locais de amostragem $^{3}$} & \multicolumn{3}{|c|}{ Locais de amostragem } \\
\hline & TS & TM & TI & TS & TM & TI \\
\hline & \multicolumn{6}{|c|}{ Densidade do solo $\left(\mathrm{kg} \mathrm{dm}^{-3}\right)$} \\
\hline M1 & $1,40 \mathrm{ABa}$ & $1,36 \mathrm{Bb}$ & $1,46 \mathrm{Aa}$ & $1,31 \mathrm{Ba}$ & $1,31 \mathrm{Bb}$ & 1,46 Аа \\
\hline M2 & $1,41 \mathrm{Aa}$ & 1,44 Аа & 1,43 Aab & 1,33 Aa & $1,30 \mathrm{Ab}$ & $1,32 \mathrm{Ab}$ \\
\hline \multirow[t]{2}{*}{ M3 } & $1,44 \mathrm{ABa}$ & 1,46 Аа & $1,37 \mathrm{Bb}$ & $1,37 \mathrm{ABa}$ & 1,38 Аа & $1,30 \mathrm{Bb}$ \\
\hline & \multicolumn{6}{|c|}{ Porosidade Total $\left(\mathrm{m}^{3} \mathrm{~m}^{-3}\right)$} \\
\hline M1 & 0,473 Аа & 0,488 Аа & $0,451 \mathrm{Ab}$ & 0,498 Аа & 0,500 Аa & $0,444 \mathrm{Ab}$ \\
\hline M2 & $0,467 \mathrm{Aa}$ & $0,457 \mathrm{Ab}$ & 0,462 Aab & 0,490 Аа & 0,503 Аа & 0,496 Аа \\
\hline \multirow[t]{2}{*}{ M3 } & 0,460 Аа & $0,448 \mathrm{Ab}$ & 0,483 Аа & 0,477 Аа & $0,471 \mathrm{Ab}$ & 0,504 Aa \\
\hline & \multicolumn{6}{|c|}{ Macroporosidade $\left(\mathrm{m}^{3} \mathrm{~m}^{-3}\right)$} \\
\hline M1 & $0,137 \mathrm{Aa}$ & 0,172 Аа & 0,142 Аа & 0,159 Аа & $0,171 \mathrm{Aa}$ & 0,121 Aa \\
\hline M2 & 0,118 Аа & $0,097 \mathrm{Ab}$ & $0,093 \mathrm{Ab}$ & 0,113 Ва & 0,125 ABab & 0,170 Aa \\
\hline \multirow[t]{2}{*}{ M3 } & 0,130 Аа & $0,086 \mathrm{Ab}$ & 0,138 Аа & 0,134 Аа & 0,099 Ab & 0,125 Aa \\
\hline & \multicolumn{6}{|c|}{ Microporosidade $\left(\mathrm{m}^{3} \mathrm{~m}^{-3}\right)$} \\
\hline M1 & 0,336 Аа & $0,316 \mathrm{Ab}$ & 0,309 Ab & 0,339 Аа & 0,329 Ab & $0,323 \mathrm{Ab}$ \\
\hline M2 & 0,349 Аа & 0,360 Аа & 0,369 Аа & 0,377 Аа & 0,378 Аа & $0,326 \mathrm{Ab}$ \\
\hline M3 & 0,330 Аа & 0,362 Аа & 0,345 Аа & 0,343 Аа & 0,372 Аа & 0,379 Аа \\
\hline
\end{tabular}

${ }^{1}$ Médias seguidas da mesma letra, maiúscula na linha e minúscula na coluna, não diferem entre si, pelo teste de Tukey a 5\%.

${ }^{2}$ M1 - irrigação por gotejamento, calagem a cada dois anos, adubação química, roçadas e uso da palha de café; M2 - adubação química, roçadas e capinas; M3 - capinas e roçadas.

${ }^{3}$ TS - terço superior; TM - terço médio; TI - terço inferior. 
Tabela 2. Valores médios da resistência do solo à penetração (RP), em MPa, nas camadas de 0,00-0,20 e 0,20-0,40 m do solo, obtidos em lavouras de cafeeiro conilon cultivadas sob distintos manejos e em diferentes locais de amostragem ${ }^{1}$

\begin{tabular}{|c|c|c|c|c|}
\hline \multirow{2}{*}{\multicolumn{2}{|c|}{ Manejos $^{2}$}} & \multicolumn{3}{|c|}{ Locais de amostragem ${ }^{3}$} \\
\hline & & TS & TM & TI \\
\hline \multicolumn{2}{|c|}{ Camada 0,00 - 0,20 m } & \multicolumn{3}{|c|}{ Camada $0,20-0,40 \mathrm{~m}$} \\
\hline $\bar{M} 1$ & $3,11 \mathrm{c}$ & $5,64 \mathrm{Ab}$ & $5,80 \mathrm{Ab}$ & $6,12 \mathrm{Ab}$ \\
\hline M2 & $3,68 \mathrm{~b}$ & $5,19 \mathrm{Ab}$ & $6,15 \mathrm{Ab}$ & $5,64 \mathrm{Ab}$ \\
\hline M3 & 5,93 a & $8,04 \mathrm{Ba}$ & $11,16 \mathrm{Aa}$ & $12,44 \mathrm{Aa}$ \\
\hline
\end{tabular}

${ }^{1}$ Médias seguidas da mesma letra, maiúscula na linha e minúscula na coluna, não diferem entre si, pelo teste de Tukey a 5\%.

${ }^{2}$ M1 - irrigação por gotejamento, calagem a cada dois anos, adubação química, roçadas e uso da palha de café; M2 - adubação química, roçadas e capinas; M3 - capinas e roçadas.

${ }^{3}$ TS - terço superior; TM - terço médio; TI - terço inferior

Tabela 3. Valores médios de umidade do solo (U), em kg kg-1 , nas camadas de 0,00-0,20 e 0,20-0,40 m do solo, obtidos em lavouras de cafeeiro conilon cultivadas sob distintos manejos ${ }^{1}$

\begin{tabular}{|c|c|c|c|c|c|}
\hline \multicolumn{3}{|c|}{ Camada 0,00 - 0,20 m } & \multicolumn{3}{|c|}{ Camada $0,20-0,40 \mathrm{~m}$} \\
\hline \multicolumn{3}{|c|}{ Manejos $^{2}$} & \multicolumn{3}{|c|}{ Manejos $^{2}$} \\
\hline M1 & M2 & M3 & M1 & M2 & M3 \\
\hline $22,0 \mathrm{~A}$ & $22,0 \mathrm{~A}$ & $16,0 \mathrm{~B}$ & $24,0 \mathrm{~A}$ & $23,0 \mathrm{~A}$ & $19,0 \mathrm{~B}$ \\
\hline
\end{tabular}

${ }^{1}$ Médias seguidas da mesma letra, maiúscula na linha, não diferem entre si, pelo teste de Tukey a 5\%.

${ }^{2}$ M1 - irrigação por gotejamento, calagem a cada dois anos, adubação química, roçadas e uso da palha de café; M2 - adubação química, roçadas e capinas; M3 - capinas e roçadas.

ser restritivos ao desenvolvimento radicular do cafeeiro. Os valores observados, segundo Camargo \& Alleoni (1997), estão na amplitude de faixa da classe de resistência alta (5,1 a $10 \mathrm{MPa})$, em que há sérias limitações para o desenvolvimento das raízes, o que possivelmente está associado aos elevados valores de densidade do solo e microporosidade (Tabela 1) e ao manejo adotado que mantêm o solo desnudo. Essas restrições ao desenvolvimento das raízes são bastante prejudiciais, principalmente, em épocas de déficit hídrico, em lavouras irrigadas e não irrigadas, o que provocaria, mesmo estando os nutrientes no solo em níveis de exigência satisfatória para a cultura do café conilon, a sua não disponibilidade para a planta, por dificuldade do movimento de água e de solutos pelo solo até a zona de absorção das raízes.

Para a camada de 0,20-0,40 m, analisando-se os locais de amostragem dentro dos tratos M1 e M2, nota-se que não houve diferença significativa entre os locais de amostragem para a resistência do solo à penetração (Tabela 2), o que demonstra que não há influência do local de amostragem para essa propriedade física do solo em profundidade. Comportamento distinto foi observado sob M3, sendo que o TS diferiu significativamente dos demais locais de amostragem.

Pela Tabela 2, ao se observarem as duas camadas estudadas, percebe-se que os maiores valores para a resistência do solo à penetração encontram-se na camada de 0,20-0,40 m, para os respectivos manejos, o que é corroborado por Gontijo (2003), o qual, trabalhando com la- voura cafeeira submetida a diferentes manejos, verificou aumento da resistência do solo à penetração com a profundidade do solo.

Considerando-se que a resistência do solo à penetração constitui-se uma medida do grau de compactação do solo, sua avaliação faz-se importante. Freddi et al. (2009), em estudo sobre compactação do solo e produção de cultivares de milho em Latossolo Vermelho, verificaram que a resistência do solo à penetração e a macroporosidade foram as propriedades físicas do solo mais sensíveis à compactação.

\section{CONCLUSÕES}

Dentre as propriedades físicas do solo estudadas, a resistência do solo à penetração, a macro e a microporosidade mostraram-se importantes indicadores físicos da qualidade do solo, influenciadas pelo manejo, local de amostragem e camada de avaliação, como também se mostraram mais sensíveis para avaliar mudanças na qualidade do solo decorrentes do manejo.

\section{REFERÊNCIAS}

Alcântara EN (1997) Efeitos de diferentes métodos de controle de plantas daninhas na cultura do cafeeiro (Coffea arabica L.) sobre a qualidade de um Latossolo Roxo distrófico. Tese de Doutorado. Universidade Federal de Lavras, Lavras, 133p.

Araújo MA, Tormena CA \& Silva AP (2004). Propriedades físicas de um Latossolo Vermelho distrófico cultivado e sob mata nativa. Revista Brasileira de Ciência do Solo, 28:337-345. 
Araújo R, Goedert WJ \& Lacerda MPC (2007). Qualidade de um solo sob diferentes usos e sob cerrado nativo. Revista Brasileira de Ciência do Solo, 31:1099-1108.

Beutler AN, Centurion, JF \& Roque, CG (2004). Relação entre alguns atributos físicos e a produção de grãos de soja e arroz de sequeiro em Latossolos. Ciência Rural, 34:365-371.

Brady NC. (1989) Natureza e propriedades do solo. $7^{\text {a }}$ ed. Rio de Janeiro, Freitas Bastos. 898p.

Camargo OA \& Alleoni LRF (1997). Compactação do solo e o desenvolvimento das plantas. Piracicaba, USP/ESALQ. 132p.

Conceição PC, Amado TJC, Mielniczuk J \& Spagnollo E (2005). Qualidade do solo em sistemas de manejo avaliada pela dinâmica da matéria orgânica e atributos relacionados. Revista Brasileira de Ciência do Solo, 29:777-788.

Dexter AR (2004). Soil physical quality. Part I. Theory, effects of soil texture, density, and organic matter, and effects on root growth. Geoderma, 120:201-214.

Embrapa (1997). Centro de Pesquisas de Solos. Manual de métodos de análise de solos. $2^{\text {a }}$ ed. Rio de Janeiro. 212p.

Embrapa (1999). Centro Nacional de Pesquisas de Solos. Sistema brasileiro de classificação de solos. Rio de Janeiro. 412p.

Freddi OS, Centurion JF, Duarte AP \& Leonel, CL (2009). Compactação do solo e produção de cultivares de milho em Latossolo Vermelho. I - características de planta, solo e índice S. Revista Brasileira de Ciência do Solo, 33:793-803.

Gontijo I (2003). Avaliação de atributos físicos em solo de cerrado sob cafeicultura em dois sistemas de manejo de plantas espontâneas, utilizando testes de hipóteses e geoestatística. Dissertação de Mestrado. Universidade Federal de Uberlândia, Uberlândia, $86 \mathrm{p}$

Guimarães PTG \& Lopes AS (1986). Solos para o cafeeiro: características, propriedades e manejo. In: Rena AB, Malavolta E, Rocha M \& Yamada T (Eds.) Cultura do cafeeiro: fatores que afetam a produtividade. Piracicaba, Associação Brasileira para Pesquisa da Potassa e o Fosfato. p.115-161.

Hatano R, Iwanaga K, Okajima H \& Sakuma T (1988). Relationship between the distribution of soil macropores and root elongation. Soil Science and Plant Nutrition, 34:535-546.

Lima CLR, Pillon CN \& Lima ACR (2007). Qualidade física do solo: indicadores quantitativos. Pelotas, Embrapa Clima Temperado. 25p (Documentos, 196).

Matiello JB (1998). Café Conilon: como plantar, tratar, colher, preparar e vender. Rio de Janeiro, MAA/SDR/PROCAFE/PNFC. $162 p$.
Matiello JB, Santinato R, Garcia AWR, Almeida SR \& Fernades DR (2005). Cultura do café no Brasil: novo manual de recomendações. Rio de Janeiro, MAPA/PROCAFE. 438 p.

Nunes LAPL, Dias LE, Jucksch I \& Barros NF (2010). Atributos físicos do solo em área de monocultivo de cafeeiro na Zona da Mata de Minas Gerais. Bioscience Journal, 26:71-78.

Pedrotti A, Ferreira MM, Curi N, Silva MLN, Lima JM \& Carvalho R (2003). Relação entre atributos físicos, mineralogia da fração argila e formas de alumínio no solo. Revista Brasileira de Ciência do Solo, 27:1-9.

Reichert JM, Reinert DJ \& Braida JA (2003). Qualidade dos solos e sustentabilidade de sistemas agrícolas. Ciência \& Ambiente, 27:29-48.

Ribon AA, Centurion JF, Centurion MAPC \& Carvalho Filho A (2002). Propriedades físicas de Latossolo e Argissolo em função de práticas de manejo aplicadas na entrelinha da cultura da seringueira (Hevea brasiliensis). Revista Brasileira de Ciência do Solo, 26:781-787.

Richart A, Tavares Filho J, Brito OR, Llanillo RF \& Ferreira R (2005). Compactação do solo: Causas e efeitos. Semina: Ciências Agrárias, 26:321-344.

Silva RR, Silva MLN \& Ferreira MM (2005). Atributos físicos indicadores da qualidade do solo sob sistemas de manejo na Bacia do Alto do Rio Grande - MG. Ciência e Agrotecnologia, 29:719-730.

Silveira DC, Melo Filho JF, Sacramento JAAS \& Silveira ECP (2010). Relação umidade versus resistência à penetração para um Argissolo Amarelo distrocoeso no recôncavo da Bahia. Revista Brasileira de Ciência do Solo, 34:659-667.

Spera ST, Santos HP, Tomm GO, Kochann RA \& Ávila A (2009). Atributos físicos do solo em sistemas de manejo de solo e de rotação de culturas. Bragantia, 68:1079-1093.

Stolf R (1991). Teoria e teste experimental de fórmulas de transformação dos dados de penetrômetro de impacto em resistência do solo. Revista Brasileira de Ciência do Solo, 15:229-235.

Vomocil JA \& Flocker WJ (1966). Effects of soil compaction on storage and movement of soil, air and water. American Society Agricultural Engineering, 4:242-246.

Watanabe SH, Tormena CA, Araújo MA, Vidigal Filho OS, Pintro JC, Costa ACS \& Muniz AS (2002). Propriedades físicas de um Latossolo Vermelho distrófico influenciadas por sistemas de preparo do solo utilizados para implantação da cultura da mandioca. Acta Scientiarum, 24:1255-1264. 